\title{
Upper Lip Anatomy, Mechanics of Local Flaps, and Considerations for Reconstruction
}

\author{
Alexis L. Boson, MD; Stefanos Boukovalas, MD; Joshua P. Hays, MD; Josh A. Hammel, MD; \\ Eric L. Cole, MD; Richard F. Wagner Jr, MD
}

\section{PRACTICE POINTS}

- Comprehensive knowledge of static and dynamic structural support is imperative in reconstruction of upper lip wounds.

- The surgeon should evaluate deficient structures as well as characteristics of the defect to select the most appropriate reconstruction method for optimal functional and aesthetic outcomes.
Reconstruction of defects involving the upper lip can be challenging. The purpose of this review was to analyze the anatomy and function of the upper lip and provide an approach for reconstruction of upper lip defects. The primary role of the upper lip is coverage of dentition and animation, whereas the lower lip is critical for oral competence, speech, and eating. The orbicularis oris $(\mathrm{OO})$ and several other muscles contribute to upper lip function. There are various insertion points for animation muscles, including the upper lip dermis, $\mathrm{OO}$, and modiolus. Special attention should be paid to the philtrum, Cupid's bow, and vermilion border during reconstruction. Advantages and disadvantages of the Abbe, Estlander, and Karapandzic flaps are presented. Knowledge of mechanics, indications, and properties of local flaps while considering unique characteristics of upper lip anatomy and function are crucial for optimal aesthetic and functional outcomes.

Cutis. 2021;107:144-148.

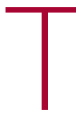
he upper lip poses challenges during reconstruction. Distortion of well-defined anatomic structures, including the vermilion border, oral commissures,
Cupid's bow, and philtrum, leads to noticeable deformities. Furthermore, maintenance of upper and lower lip function is essential for verbal communication, facial expression, and controlled opening of the oral cavity.

Similar to a prior review focused on the lower lip, ${ }^{1}$ we conducted a review of the literature using the PubMed database (1976-2017) and the following search terms: upper lip, lower lip, anatomy, comparison, cadaver, histology, local flap, and reconstruction. We reviewed studies that assessed anatomic and histologic characteristics of the upper and the lower lips, function of the upper lip, mechanics of local flaps, and upper lip reconstruction techniques including local flaps and regional flaps. Articles with an emphasis on free flaps were excluded.

The initial search resulted in 1326 articles. Of these, 1201 were excluded after abstracts were screened. Fulltext review of the remaining 125 articles resulted in exclusion of 85 papers (9 foreign language, 4 duplicates, and 72 irrelevant). Among the 40 articles eligible for inclusion, 12 articles discussed anatomy and histology of the upper lip, 9 examined function of the upper lip, and 19 reviewed available techniques for reconstruction of the upper lip.

In this article, we review the anatomy and function of the upper lip as well as various repair techniques to provide the reconstructive surgeon with greater familiarity with the local flaps and an algorithmic approach for upper lip reconstruction.

\section{Anatomic Characteristics of the Upper Lip}

The muscular component of the upper lip primarily is comprised of the orbicularis oris (OO) muscle divided

Drs. Boson, Cole, and Wagner are from The University of Texas Medical Branch, Galveston. Drs. Boson and Cole are from the Division of Plastic Surgery, Department of Surgery, and Dr. Wagner is from the Department of Dermatology. Dr. Boukovalas is from the Division of Plastic and Reconstructive Surgery, Department of Surgery, The University of Tennessee Graduate School of Medicine, Knoxville. Dr. Hays is from the Department of Emergency Medicine, Baylor College of Medicine, Houston, Texas. Dr. Hammel is from Dermatology Specialists, Atlanta, Georgia The authors report no conflict of interest.

The eTable is available in the Appendix online at www.mdedge.com/dermatology.

Correspondence: Stefanos Boukovalas, MD, Division of Plastic and Reconstructive Surgery, Department of Surgery, The University of Tennessee Graduate School of Medicine, Knoxville, TN 37920 (stefbouk@gmail.com).

doi:10.12788/cutis.0205 
into 2 distinct concentric components: pars peripheralis and pars marginalis. ${ }^{2,3}$ It is discontinuous in some individuals. ${ }^{4}$ Although $\mathrm{OO}$ is the primary muscle of the lower lip, the upper lip is remarkably complex. Orbicularis oris and 3 additional muscles contribute to upper lip function: depressor septi nasi, the alar portion of the nasalis, and levator labii superioris alaeque nasi (LLSAN)..$^{5}$

The modiolus, a muscular structure located just lateral to the commissures, serves as a convergence point for facial muscle animation and lip function while distributing contraction forces between the lips and face. ${ }^{6}$ It is imperative to preserve its location in reconstruction to allow for good functional and aesthetic outcomes.

The upper lip is divided into 3 distinct aesthetic subunits: the philtrum and 1 lateral subunit on each side. ${ }^{7,8}$ Its unique surface features include the Cupid's bow, vermilion tubercle, and philtral columns. The philtral columns are created by the dermal insertion on each side of the $\mathrm{OO}$, which originates from the modiolus, decussates, and inserts into the skin of the contralateral philtral groove. ${ }^{2,9-11}$ The $\mathrm{OO}$ has additional insertions into the dermis lateral to the philtrum. ${ }^{5}$ During its course across the midline, it decreases its insertions, leading to the formation and thinness of the philtral dimple. ${ }^{9}$ The philtral shape primarily is due to the intermingling of LLSAN and the pars peripheralis in an axial plane. The LLSAN enters superolateral to the ipsilateral philtral ridge and courses along this ridge to contribute to the philtral shape. ${ }^{2}$ Formation of the philtrum's contour arises from the opposing force of both muscles pulling the skin in opposite directions. ${ }^{2,5}$ The vermilion tubercle arises from the dermal insertion of the pars marginalis originating from the ipsilateral modiolus and follows the vermilion border. ${ }^{2}$ The Cupid's bow is part of the white roll at the vermilion-cutaneous junction produced by the anterior projection of the pars peripheralis. ${ }^{10}$ The complex anatomy of this structure explains the intricacy of lip reconstructions in this area.

\section{Function of the Upper Lip}

Although the primary purpose of $\mathrm{OO}$ is sphincteric function, the upper lip's key role is coverage of dentition and facial animation. ${ }^{12}$ The latter is achieved through the relationship of multiple muscles, including levator labii superioris, levator septi nasi, risorius, zygomaticus minor, zygomaticus major, levator anguli oris, and buccinator. ${ }^{7,13-17}$ Their smooth coordination results in various facial expressions. In comparison, the lower lip is critical for preservation of oral competence, prevention of drooling, eating, and speech due to the actions of $\mathrm{OO}$ and vertical support from the mentalis muscle. ${ }^{1,18-22}$

\section{Reconstructive Methods for the Upper Lip}

Multiple options are available for reconstruction of upper lip defects, with the aim to preserve facial animation and coverage of dentition. When animation muscles are involved, restoring function is the goal, which can be achieved by placing sutures to reapproximate the muscle edges in smaller defects or anchor the remaining muscle edge to preserve deep structures in larger defects, respecting the vector of contraction and attempting simulation of the muscle function. Additionally, restoration of the continuity of $\mathrm{OO}$ also is important for good aesthetic and functional outcomes.

Janis $^{23}$ proposed the rule of thirds to approach upper and lower lip reconstruction. Using these rules, we briefly analyze the available flaps focusing on animation, $\mathrm{OO}$ restoration, preservation of the modiolus position, and sensation for each (eTable).

The perialar crescentic flap, an advancement flap, can be utilized for laterally located partial-thickness defects affecting up to one-third of the upper lip, especially those adjacent to the alar base, as well as full-thickness defects affecting up to two-thirds of the upper lip., The $\mathrm{OO}$ continuity and position of the modiolus often are preserved, sensation is maintained, and muscles of animation commonly are unaffected by this flap, especially in partial-thickness defects. In males, caution should be exercised where non-hair-bearing skin of the cheek is advanced to the upper lip region. Other potential complications include obliteration of the melolabial crease and pincushioning. ${ }^{7}$

Nasolabial (ie, melolabial) flaps are suggested for repair of defects up to one-third of the upper lip, especially when the vermilion is unaffected, or in lateral defects with or without commissure involvement. ${ }^{7,24-28}$ This flap is based on the facial artery and may be used as a direct transposition, V-Y advancement, or island flap with good aesthetic and functional outcomes (Figure 1).29,30 There is limited literature regarding the effects on animation. However, it may be beneficial in avoiding microstomia, as regional tissue is transferred from the cheek area, maintaining upper lip length. Additionally, the location of the modiolus often is unaffected, especially when the flap is harvested above the level of the muscle, providing superior facial animation function. Flap design is critical in areas lateral to the commissure and over the modiolus, as distortion of its position can occur. ${ }^{26}$ Similar to crescentic advancement, it is important to exercise caution in male patients, as non-hair-bearing tissue can be transferred to the upper lip. Reported adverse outcomes of the nasolabial flap include a thin flat upper lip, obliteration of the Cupid's bow, and hypoesthesia that may improve over time. ${ }^{30}$

The Abbe flap is suitable for reconstruction of upper lip defects affecting up to two-thirds of the upper lip and lateral defects, provided the commissure or philtrum is unaffected. ${ }^{7,8}$ It is a 2-stage lip-switch flap based on the inferior labial artery, where tissue is harvested and transferred from the lower lip (Figure 2). ${ }^{23,31}$ It is particularly useful for philtral reconstruction, as incision lines at the flap edges can recreate the skin folds of the philtrum. Moreover, incision lines are better concealed under the nose, making it favorable for female patients. 
Surgeons should consider the difference in philtral width between sexes when designing this flap for optimal aesthetic outcome, as males have larger philtral width than females. ${ }^{21}$ The Abbe flap allows preservation of the Cupid's bow, oral commissure, and modiolus position; however, it is an insensate flap and does not establish continuity of $\mathrm{OO}^{23}$ For central defects, the function of animation muscles is not critically affected. In philtral reconstruction using an Abbe flap, a common adverse outcome is widening of the central segment because of tension and contraction forces applied by the adjacent OO. Restoration of the continuity of the muscle through dissection and advancement in small defects or anchoring of muscle edges on deeper surfaces may avoid direct pull on the flap. In larger central defects extending beyond the native philtrum, it is important to recreate the philtrum proportional to the remaining upper and lower lips. The recommended technique is a combination of a thin Abbe flap with bilateral perialar crescentic advancement flaps to maintain a proportional philtrum. Several variations have been described, including 3D planning with muscular suspension for natural raised philtral columns, avoiding a flat upper lip. ${ }^{5}$

The Yu flap, a sensate single-stage rotational advancement flap, can be used in a variety of ways for repair of upper lip defects, depending on the size and location. ${ }^{26}$ Lateral defects up to one-half of the upper lip should be repaired with a unilateral reverse Yu flap, central defects up to one-half of the upper lip can be reconstructed with bilateral reverse Yu flaps, and defects up to two-thirds of the upper lip can be

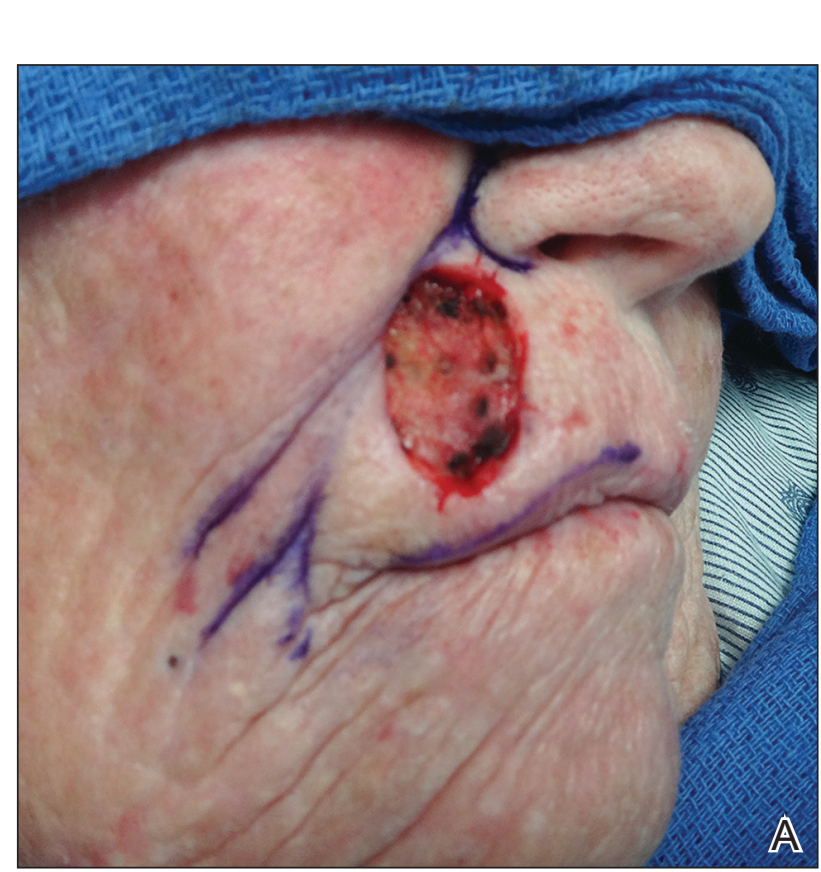

repaired with bilateral Yu flaps. This flap restores $\mathrm{OO}$ continuity and thus preserves sphincter function, minimizes oral incompetence, and has a low risk of microstomia. The muscles of facial animation are preserved, yet the modiolus is not. Good aesthetic outcomes have been reported depending on the location of the Yu flap because scars can be placed in the nasolabial sulcus, commissures, or medially to recreate the philtrum. ${ }^{26}$

The Estlander flap is a single-stage flap utilizing donor tissue from the opposing lip for reconstruction of lateral defects up to two-thirds of the upper lip with commissure and philtrum involvement (Figure 3). ${ }^{8,23,32}$ It is an insensate flap that alters the position of the modiolus, distorting oral and facial animation. ${ }^{23}$ The superomedial position of the modiolus is better tolerated in the upper lip because it increases the relaxation tone of the lower lip and simulates the vector of contraction of major animation muscles, positively impacting the sphincteric function of the reconstructed lip. Sphincteric function action is not as impaired compared with the lower lip because the new position of the modiolus tightens the lower lip and prevents drooling. ${ }^{33}$ When designing the flap, one should consider that the inferior labial artery has been reported to remain with $10 \mathrm{~mm}$ of the superior border of the lower lip; therefore, pedicles of the Abbe and Estlander flaps should be at least $10 \mathrm{~mm}$ from the vermilion border to preserve vascular supply. ${ }^{34,35}$

The Gilles fan flap, an insensate advancement rotation flap, can be employed for central and lateral full-thickness defects up to two-thirds of the upper lip not involving the commissures. ${ }^{8}$ It is a single-stage flap in which the remaining lip is redistributed and rotated

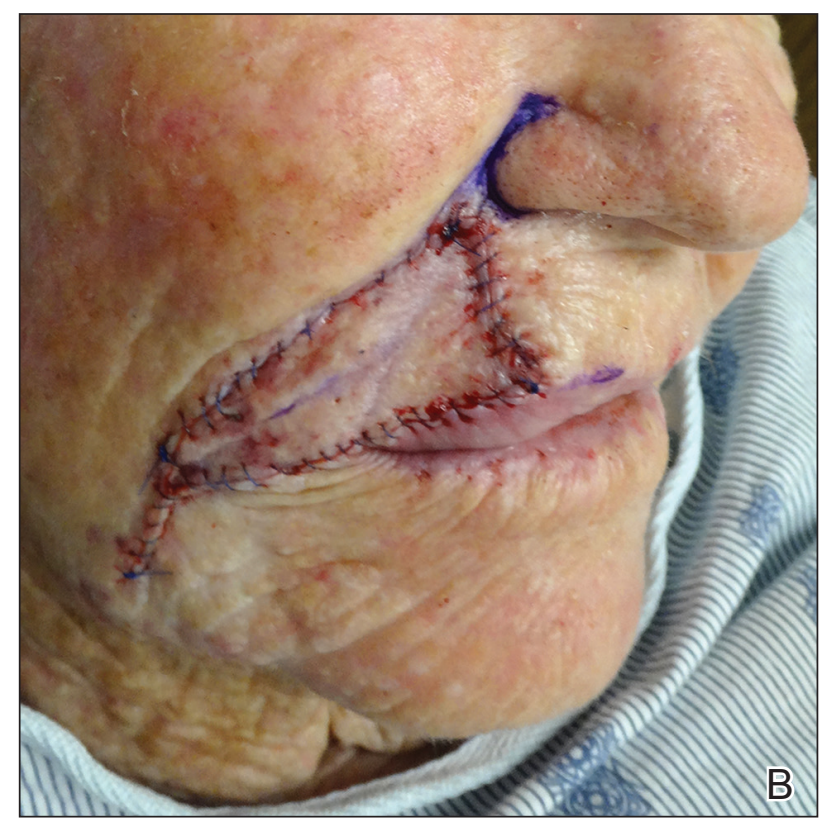

FIGURE 1. A, A patient with a $2.6 \times 2-\mathrm{cm}$ wound of the right upper lip following Mohs micrographic surgery stage 1. B, The defect was repaired using a $17.5-\mathrm{cm}^{2}$ advancement flap with musculocutaneous pedicle. 

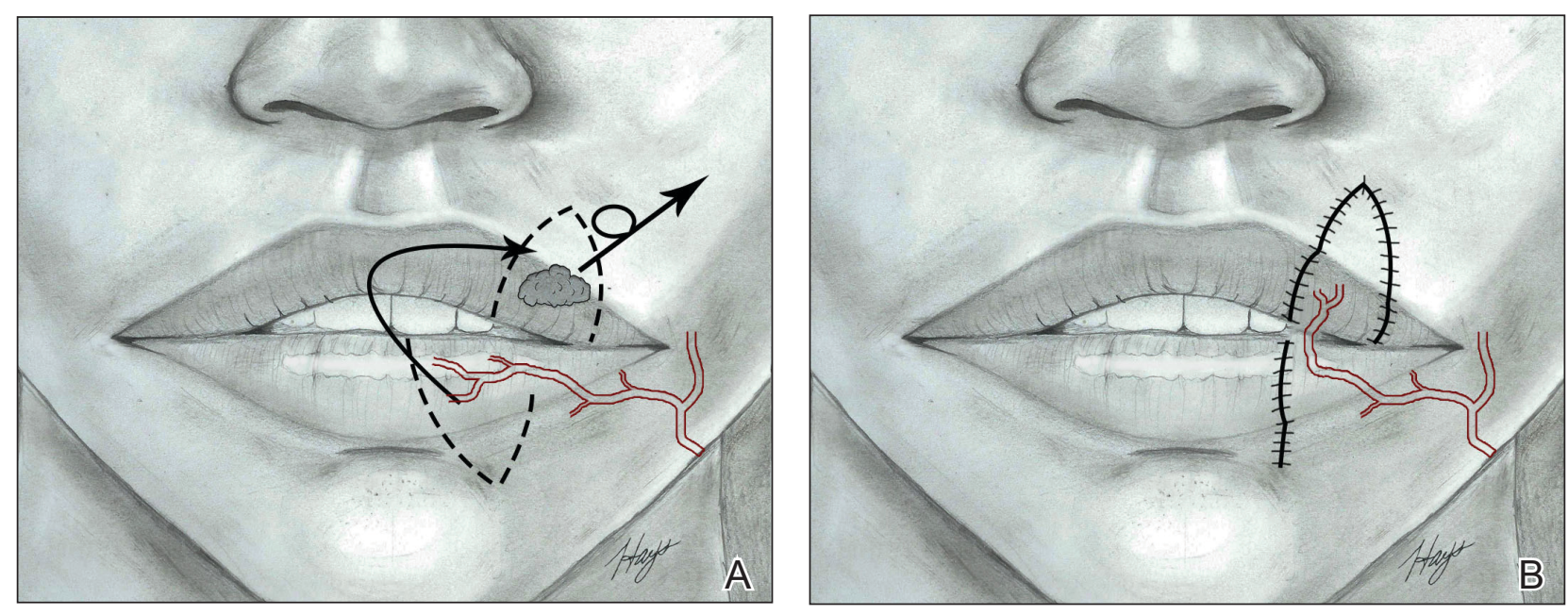

FIGURE 2. An Abbe flap. A, Design. Obtains blood supply from the ipsilateral artery. B, Flap inset with pedicle in place. It is divided 14 to 21 days later. Illustrations courtesy of Joshua P. Hays, MD (Houston, Texas).

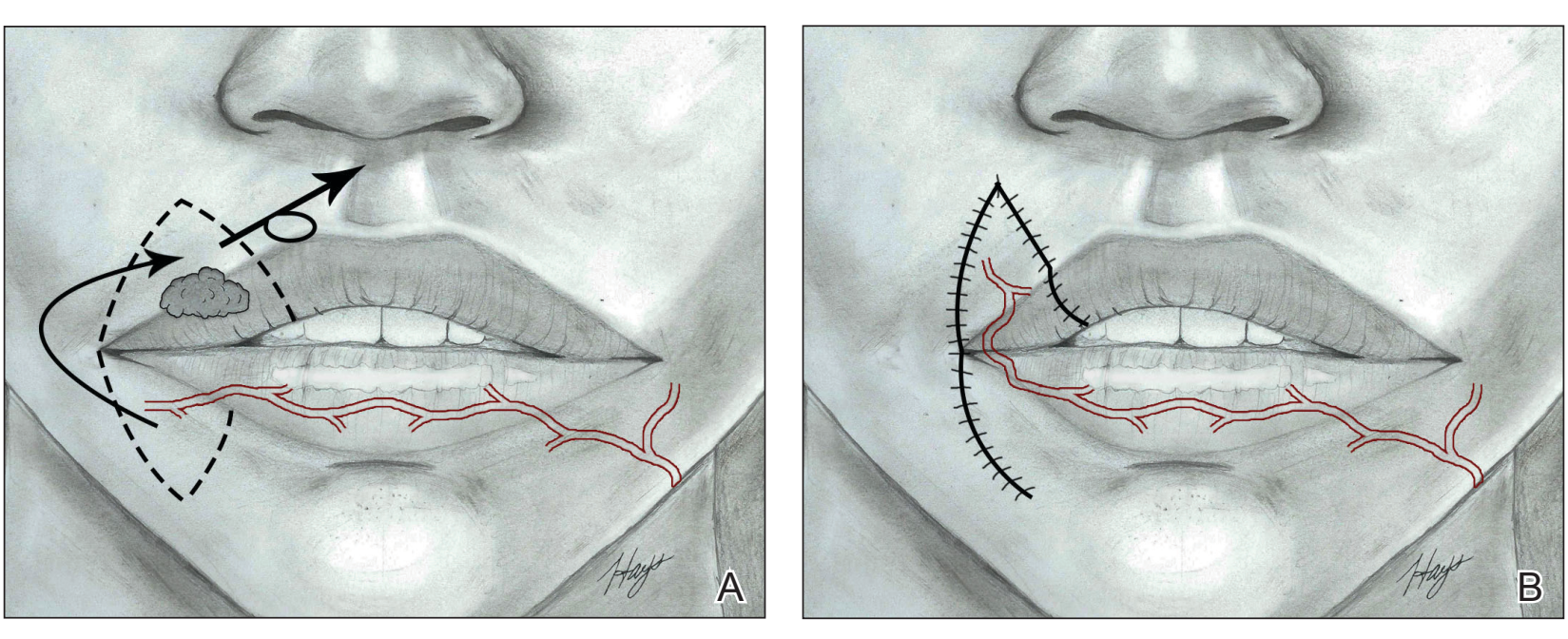

FIGURE 3. An Estlander flap. A, Design. Obtains blood supply from the contralateral labial artery. B, Flap inset and donor site closure. Illustrations courtesy of Joshua P. Hays, MD (Houston, Texas).

to create a neocommissure, but it does not restore the philtrum. Given that increased adjacent tissue is available, there is a decreased risk for microstomia. ${ }^{12}$ Facial animation is impaired because of the altered position of the modiolus and disruption of animation muscles. Oral competency is abolished, as neurovascular structures are not preserved. ${ }^{7}$ Although it has been recommended for use in total upper lip reconstruction, caution should be exercised, as use in defects greater than two-thirds can displace the modiolus and create microstomia. ${ }^{7,36}$

The Karapandzic flap, a modified Gilles fan flap, can be employed for repair of central defects up to two-thirds of the upper lip. ${ }^{8,23,32,36-39}$ The bilateral advancement of full-thickness adjacent tissue edges preserves neurovascular structures allowing sensation and restores $O O$ continuation. ${ }^{40}$ Prior studies have shown the average distance of the superior labial artery emergence from the facial artery and labial commissure is $12.1 \mathrm{~mm}$; thus, at least $12.1 \mathrm{~mm}$ of tissue from the commissure should be preserved to prevent vascular compromise in Karapandzic flaps. ${ }^{34,35}$ The modiolus position is altered, and facial animation muscles are disrupted, consequently impairing facial animation, especially elevation of the lip. ${ }^{36}$ The philtrum is obliterated, producing unfavorable aesthetic outcomes. Finally, the upper lip is thinner and smaller in volume than the lower lip, increasing the risk for microstomia compared with the lower lip with a similar reconstructive technique. ${ }^{36}$

Defects larger than two-thirds of the upper lip require a Bernard Burrow flap, distant free flap, or combination of multiple regional and local flaps dependent on the characteristics of the defect. ${ }^{36,41}$ Distant free flaps are beyond the scope of this review. The Bernard Burrow flap consists of bilaterally opposing cheek advancement flaps. It is an insensate flap that does not restore OO continuity, 
producing minimal muscle function and poor animation. Microstomia is a common adverse outcome. ${ }^{36}$

\section{Conclusion}

Comprehensive understanding of labial anatomy and its intimate relationship to function and aesthetics of the upper lip are critical. Flap anatomy and mechanics are key factors for successful reconstruction. The purpose of this article is to utilize knowledge of histology, anatomy, and function of the upper lip to improve the outcomes of reconstruction. The Abbe flap often is utilized for reconstruction of the philtrum and central upper lip defects, though it is a less desirable option for lower lip reconstruction. The Karapandzic flap, while sensate and restorative of $\mathrm{OO}$ continuity, may have less optimal functional and cosmetic results compared with its use in the lower lip. Regarding lateral defects involving the commissure, the Estlander flap provides a reasonable option for the upper lip when compared with its use in lower lip defects, where outcomes are usually inferior.

\section{REFERENCES}

1. Boukovalas S, Boson AL, Hays JP, et al. A systematic review of lower lip anatomy, mechanics of local flaps, and special considerations for lower lip reconstruction. J Drugs Dermatol. 2017;16:1254-1261.

2. Wu J, Yin N. Detailed anatomy of the nasolabial muscle in human fetuses as determined by micro-CT combined with iodine staining. Ann Plast Surg. 2016;76:111-116.

3. Pepper JP, Baker SR. Local flaps: cheek and lip reconstruction. JAMA Facial Plast Surg. 2013;15:374-382.

4. Rogers CR, Weinberg SM, Smith TD, et al. Anatomical basis for apparent subepithelial cleft lip: a histological and ultrasonographic survey of the orbicularis oris muscle. Cleft Palate Craniofac J. 2008;45:518-524.

5. Yin N, Wu D, Wang Y, et al. Complete philtrum reconstruction on the partial-thickness cross-lip flap by nasolabial muscle tension line group reconstruction in the same stage of flap transfer. JAMA Facial Plast Surg. 2017;19:496-501.

6. Al-Hoqail RA, Abdel Meguid EM. An anatomical and analytical study of the modiolus: enlightening its relevance to plastic surgery. Aesthetic Plast Surg. 2009;33:147-152.

7. Galyon SW, Frodel JL. Lip and perioral defects. Otolaryngol Clin North Am. 2001;34:647-666.

8. Massa AF, Otero-Rivas M, González-Sixto B, et al. Combined cutaneous rotation flap and myomucosal tongue flap for reconstruction of an upper lip defect. Actas Dermosifiliogr. 2014;105:869-871.

9. Latham RA, Deaton TG. The structural basis of the philtrum and the contour of the vermilion border: a study of the musculature of the upper lip. J Anat. 1976;121:151-160.

10. Garcia de Mitchell CA, Pessa JE, Schaverien MV, et al. The philtrum: anatomical observations from a new perspective. Plast Reconstr Surg. 2008;122:1756-1760.

11. Bo C, NingbeiY. Reconstruction of upper lip muscle system by anatomy, magnetic resonance imaging, and serial histological sections. J Craniofac Surg. 2014;25:48-54.

12. Ishii LE, Byrne PJ. Lip reconstruction. Facial Plast Surg Clin North Am. 2009;17:445-453.

13. Hur MS, Youn $\mathrm{KH}, \mathrm{Hu} \mathrm{KS}$, et al. New anatomic considerations on the levator labii superioris related with the nasal ala. J Craniofac Surg. 2010;21:258-260.

14. Song R, Ma H, Pan F. The "levator septi nasi muscle" and its clinical significance. Plast Reconstr Surg. 2002;109:1707-1712; discussion 1713.

15. Choi DY, Hur MS, Youn KH, et al. Clinical anatomic considerations of the zygomaticus minor muscle based on the morphology and insertion pattern. Dermatol Surg. 2014;40:858-863.
16. Youn KH, Park JT, Park DS, et al. Morphology of the zygomaticus minor and its relationship with the orbicularis oculi muscle. J Craniofac Surg. 2012;23:546-548.

17. Vercruysse H, Van Nassauw L, San Miguel-Moragas J, et al. The effect of a Le Fort I incision on nose and upper lip dynamics: unraveling the mystery of the "Le Fort I lip." J Craniomaxillofac Surg. 2016;44:1917-1921.

18. Vinkka-Puhakka H, Kean MR, Heap SW. Ultrasonic investigation of the circumoral musculature. J Anat. 1989;166:121-133.

19. Ferrario VF, Rosati R, Peretta R, et al. Labial morphology: a 3-dimensional anthropometric study. J Oral Maxillofac Surg. 2009;67:1832-1839.

20. Ferrario VF, Sforza C, Schmitz JH, et al. Normal growth and development of the lips: a 3-dimensional study from 6 years to adulthood using a geometric model. J Anat. 2000;196:415-423.

21. Sforza C, Grandi G, Binelli M, et al. Age- and sex-related changes in threedimensional lip morphology. Forensic Sci Int. 2010;200:182.e181-187.

22. Wilson DB. Embryonic development of the head and neck: part 3, the face. Head Neck Surg. 1979;2:145-153.

23. Janis JE, ed. Essentials of Plastic Surgery. 2nd ed. Boca Raton, FL: Taylor \& Francis Group; 2014.

24. Burusapat C, Pitiseree A. Advanced squamous cell carcinoma involving both upper and lower lips and oral commissure with simultaneous reconstruction by local flap: a case report. J Med Case Rep. 2012;6:23.

25. El-Marakby HH. The versatile naso-labial flaps in facial reconstruction. J Egypt Natl Canc Inst. 2005;17:245-250.

26. Li ZN, Li RW, Tan XX, et al.Yu's flap for lower lip and reverse Yu's flap for upper lip reconstruction: 20 years experience. Br J Oral Maxillofac Surg. 2013;51:767-772.

27. Wollina U. Reconstructive surgery in advanced perioral nonmelanoma skin cancer. Results in elderly patients. J Dermatol Case Rep. 2014;8:103-107.

28. Younger RA. The versatile melolabial flap. Otolaryngol Head Neck Surg. 1992;107:721-726.

29. Włodarkiewicz A, Wojszwiłło-Geppert E, Placek W, et al. Upper lip reconstruction with local island flap after neoplasm excision. Dermatol Surg. 1997;23:1075-1079.

30. Cook JL. The reconstruction of two large full-thickness wounds of the upper lip with different operative techniques: when possible, a local flap repair is preferable to reconstruction with free tissue transfer. Dermatol Surg. 2013;39:281-289.

31. Kriet JD, Cupp CL, Sherris DA, et al. The extended Abbé flap. Laryngoscope. 1995;105:988-992.

32. Khan AA, Kulkarni JV. Karapandzic flap. Indian J Dent. 2014;5:107-109.

33. Raschke GF, Rieger UM, Bader RD, et al. Lip reconstruction: an anthropometric and functional analysis of surgical outcomes. Int J Oral Maxillofac Surg. 2012;41:744-750.

34. Mağden O, Edizer M, Atabey A, et al. Cadaveric study of the arterial anatomy of the upper lip. Plast Reconstr Surg. 2004;114:355-359.

35. Al-Hoqail RA, Meguid EM. Anatomic dissection of the arterial supply of the lips: an anatomical and analytical approach. J Craniofac Surg. 2008;19:785-794.

36. Kim JC, Hadlock T, Varvares MA, et al. Hair-bearing temporoparietal fascial flap reconstruction of upper lip and scalp defects. Arch Facial Plast Surg. 2001;3:170-177.

37. Teemul TA, Telfer A, Singh RP, et al. The versatility of the Karapandzic flap: a review of 65 cases with patient-reported outcomes. J Craniomaxillofac Surg. 2017;45:325-329.

38. Matteini C, Mazzone N, Rendine G, et al. Lip reconstruction with local m-shaped composite flap. J Craniofac Surg. 2010;21:225-228.

39. Williams EF, Setzen G, Mulvaney MJ. Modified Bernard-Burow cheek advancement and cross-lip flap for total lip reconstruction. Arch Otolaryngol Head Neck Surg. 1996;122:1253-1258.

40. Jaquet $\mathrm{Y}$, Pasche P, Brossard E, et al. Meyer's surgical procedure for the treatment of lip carcinoma. Eur Arch Otorhinolaryngol. 2005;262:11-16.

41. Dang M, Greenbaum SS. Modified Burow's wedge flap for upper lateral lip defects. Dermatol Surg. 2000;26:497-498. 
APPENDIX

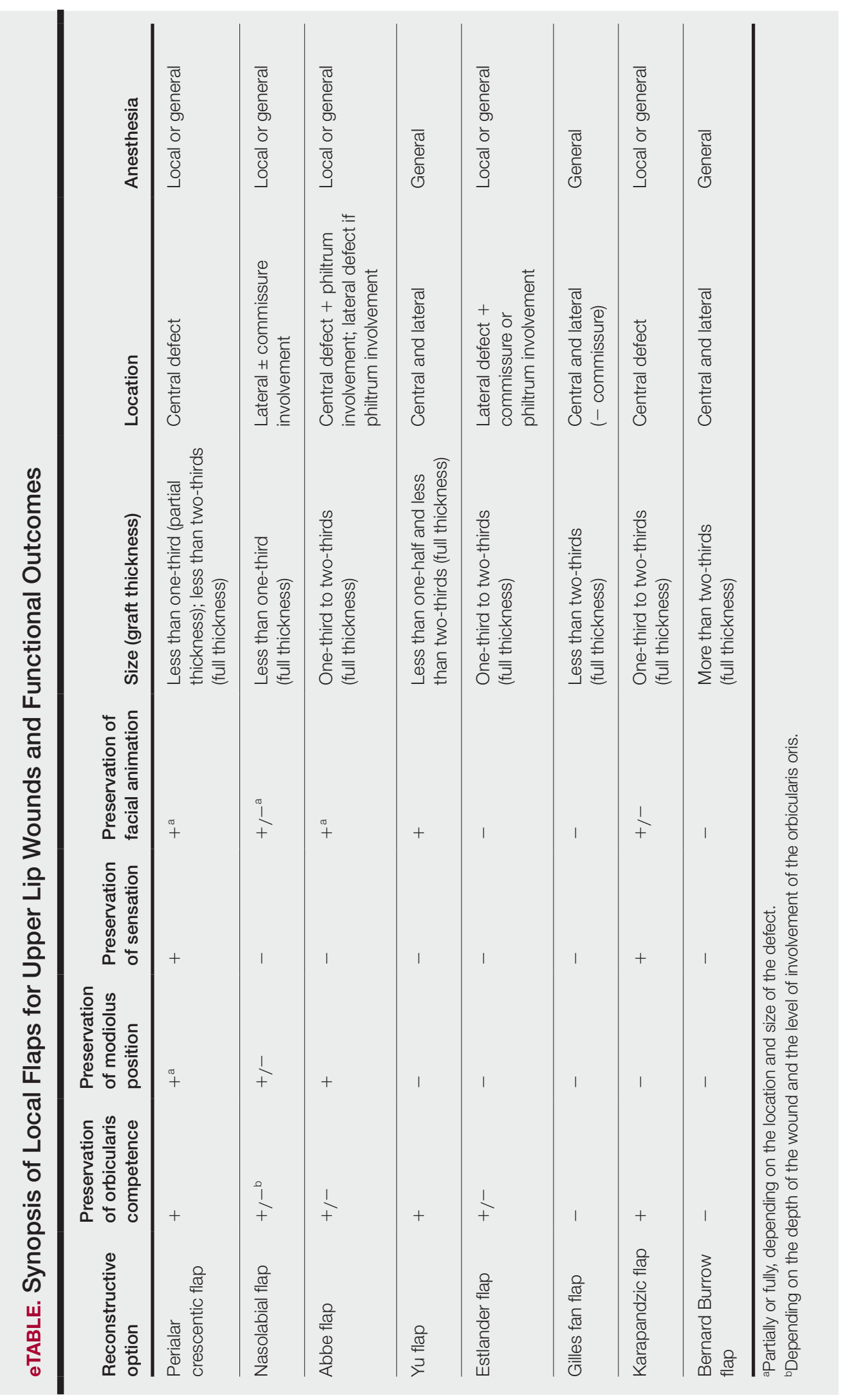

